\title{
The science of taste
}

\author{
Ole G Mouritsen
}

\begin{abstract}
An understanding and description of our sensory perception of food requires input from many different scientific disciplines: in addition to the natural and life sciences, human sciences, social sciences, as well as the arts each contributes their perspective on what we call taste. For the natural sciences, the key concept is flavor encompassing all physical, chemical, and neurophysiological aspects. For researchers in human sciences, psychology, anthropology, and social sciences, taste is a broader concept related to tradition, geography, culture, as well as social relations. For cooks and practitioners, taste is a multimodal facet of food and the way we perceive and enjoy it. An interdisciplinary symposium on The Science of Taste brought together in August 2014 researchers and practitioners who deal with taste from many different perspectives with an aim to provide a composite mosaic of our current understanding of taste.
\end{abstract}

Keywords: Taste, Flavor, Research, Science, Cooking

In contrast to smell and the olfactory system, for which the 2004 Nobel Prize in Physiology and Medicine was awarded to Richard Axel and Linda Buck for their discovery of odorant receptors and the organization of the olfactory system [1], our knowledge of the physiological basis for the taste system is considerably less developed [2]. Some progress has been obtained over the last decade by the finding of receptors or receptor candidates for all five basic tastes, bitter, sweet, umami, sour, and salty. The receptors for bitter, sweet, and umami appear to belong to the same superfamily of G-protein-coupled receptors, whereas the receptor for salty is an ion channel. The receptor function for sour is the least understood but may involve some kind of proton sensing.

Notwithstanding the prominent status of physiology of taste and its molecular underpinnings, the multisensory processing and integration of taste with other sensory inputs (sight, smell, sound, mouthfeel, etc.) in the brain and neural system have also received an increasing attention, and an understanding is emerging of how taste relates to learning, perception, emotion, and memory [3]. Similarly, the psychology of taste and how taste dictates food choice, acceptance, and hedonic behavior are in the process of being uncovered [4]. Development of

\footnotetext{
Correspondence: ogm@memphys.sdu.dk

MEMPHYS, Center for Biomembrane Physics and TASTEforLIFE, Department of Physics, Chemistry, and Pharmacy, University of Southern Denmark,
} Campusvej 55, DK-5230 Odense M, Denmark taste preferences in children and gustatory impairment in sick and elderly are now studied extensively to understand the nature of taste and the use of this insight to improve the quality of life.

Finally, a new direction has manifested itself in recent years where scientists and creative chefs apply scientific methods to gastronomy in order to explore taste in traditional and novel dishes and use physical sciences to characterize foodstuff, cooking, and flavor [5-8].

Noting that in general our understanding of taste is inferior to our knowledge of the other human senses, an interdisciplinary symposium, The Science of Taste, took place in August 2014 and brought together an international group of scientists and practitioners from a range of different disciplines (biophysics, physiology, sensory sciences, neuroscience, nutrition, psychology, epidemiology, food science, gastronomy, gastroscience, and anthropology) to discuss progress in the science of taste. As a special feature, the symposium organized two tasting events arranged by leading chefs, demonstrating the interaction between creative chefs and scientists.

The symposium led to the following special collection of papers accounting for our current knowledge about the science of taste. The collection includes a selection of opinion articles, short reports, and reviews, in addition to three research papers.

The papers deal with the following topics: the comparative biology of taste [9]; fat as a basic taste [10]; umami 
taste in relation to gastronomy [11]; the mechanism of kokumi taste [12]; geography as a starting point for deliciousness [13], temporal design of taste and flavor [14]; the pleasure principle of flavors [15]; taste as a cultural activity [16]; taste preferences in primary school children [17]; taste and appetite [18]; umami taste in relation to health [19]; taste receptors in the gastrointestinal tract [20]; neuroenology and the taste of wine [21]; the brain mechanisms behind pleasure [22]; the importance of sound for taste [23]; as well the effect of kokumi substances on the flavor of particular food items $[24,25]$.

\section{Competing interests}

The author declares that he has no competing interests.

\section{Acknowledgements}

The author wishes to thank all speakers and participants at the International Symposium on The Science of Taste for enthusiasm, criticism, and constructive discussions on all aspects of taste, science, cooking, and gastronomy. The symposium was supported financially by the Royal Danish Academy of Sciences and Letters, the Carlsberg Foundation, the Umami Information Center, and the Danish center for taste TASTEforLIFE (supported by the Nordea Foundation). Particular thanks are due to Dr. Kumiko Ninomiya and Dr. Ana San Gabriel from the Umami Information Center for help with the planning of the Symposium.

The work by the author is supported by TASTEforLIFE, a national Danish center for taste financed by the Nordea Foundation.

Received: 17 December 2014 Accepted: 30 December 2014

Published online: 26 January 2015

\section{References}

1. Buck $L$, Axel R. A novel multigene family may encode odorant receptors: a molecular basis for odor recognition. Cell. 1991; 65:175-87.

2. Nature Outlook. Making sense of flavour. Nature. 2012; 486:S1-S48.

3. Shepherd G. Neurogastronomy. New York: Columbia University Press; 2012.

4. Stevenson RJ. The psychology of flavour. Oxford: Oxford University Press; 2009.

5. This H. Molecular gastronomy. New York: Columbia University Press; 2002.

6. Vega C, Ubbink J, van der Linden E (eds): The kitchen as a laboratory. New York: Columbia University Press, 2012.

7. Mouritsen OG, Risbo J (eds). The emerging science of gastrophysics. Flavour 2013; 2:2-2:12

8. Mouritsen OG, Styrbæk K, Umami. Unlocking the secrets of the fifth taste. New York: Columbia University Press; 2012

9. Beauchamp GK, Jiang P. Comparative biology of taste: insights into mechanism and function. Flavour 2015, 4:9

10. Keast $R$, Costanzo A. Is fat the sixth taste primary? Evidence and implications. Flavour 2015, 4:5

11. Ninomiya K. Science of umami taste: adaptation to gastronomic culture. Flavour 2015, 4:13

12. Kuroda M, Naohiro Miyamura N. Mechanism of the perception of "kokumi" substances and the sensory characteristics of the "kokumi" peptide, Y-Glu-Val-Gly. Flavour 2015, 4:11

13. Evans J, Flore R, Pedersen JA, Frøst, MB. Place-based taste: geography as starting point for deliciousness. Flavour 2015, 4:7

14. Kawasaki H, Shimomura K. Temporal design of taste and flavor: practical collaboration between chef and scientist. Flavour 2015, 4:12

15. Prescott J. Flavours: The pleasure principle. Flavour 2015, 4:15

16. Pedersen $\mathrm{SH}$. Tasting as a social sense: rethinking taste as a cultural activity. Flavour 2015, 4:6

17. Ahrens W (on behalf of the IDEFICS consortium). Sensory taste preferences and taste sensitivity and the association of unhealthy food patterns with overweight and obesity in primary school children in Europe-a synthesis of data from the IDEFICS study. Flavour 2015, 4:8

18. Møller P. Taste and appetite. Flavour 2015, 4:4

19. Sasano T, Satoh-Kuriwada S, Shoji N. The important role of umami taste in oral and overall health. Flavour 2015, 4:10
20. San Gabriel AM. Taste receptors in the gastro-intestinal system. Flavour 2015, 4:14

21. Shepherd G. Neuroenology: How the brain creates the taste of wine Flavour 2015, 4:20

22. Kringelbach ML. The pleasure of food: underlying brain mechanisms of eating and other pleasures. Flavour 2015 4:19

23. Spence C. Eating with our ears: Assessing the importance of the sounds of consumption to our perception and enjoyment of multisensory flavour experiences. Flavour 2015, 4:3

24. Miyamura N, Jo S, Motonaka Kuroda M, Kouda T. Flavour improvement of reduced-fat peanut butter by addition of a kokumi peptide, gammaglutamyl-valyl-glycine. Flavour 2015, 4:16

25. Miyaki T, Kawasaki H, Kuroda M, Miyamura N, Tohru Kouda T. Effect of a kokumi peptide, gamma-glutamyl-valyl-glycine, on the sensory characteristics of chicken consommé. Flavour 2015, 4:17

\section{Submit your next manuscript to BioMed Central and take full advantage of:}

- Convenient online submission

- Thorough peer review

- No space constraints or color figure charges

- Immediate publication on acceptance

- Inclusion in PubMed, CAS, Scopus and Google Scholar

- Research which is freely available for redistribution

Submit your manuscript at www.biomedcentral.com/submit 